\begin{tabular}{|l|l|l||}
\hline \multicolumn{2}{|c|}{ PublisherInfo } \\
\hline \hline PublisherName & $:$ & BioMed Central \\
\hline \hline PublisherLocation & $:$ & London \\
\hline \hline PublisherImprintName & $:$ & BioMed Central \\
\hline \hline
\end{tabular}

\title{
Genome-wide scan in osteoarthritis
}

\begin{tabular}{||l|l|l||}
\hline \multicolumn{2}{|c||}{ ArticleInfo } \\
\hline \hline ArticleID & $:$ & 228 \\
\hline \hline ArticleDOI & $:$ & $10.1186 /$ ar-1999-66750 \\
\hline \hline ArticleCitationID & $:$ & 66750 \\
\hline \hline ArticleSequenceNumber & $:$ & 185 \\
\hline \hline ArticleCategory & $:$ & Paper Report \\
\hline \hline ArticleFirstPage & $:$ & 1 \\
\hline \hline ArticleLastPage & $:$ & 3 \\
\hline \hline & & RegistrationDate : 1999-11-11 \\
ArticleHistory & $:$ & OnlineDate $: 1999-11-11$ \\
\hline \hline ArticleCopyright & $:$ & Current Science Ltd1999 \\
\hline \hline ArticleGrants & $:$ & \\
\hline \hline ArticleContext & $:$ & 130753311 \\
\hline \hline
\end{tabular}


Tim Vyse, ${ }^{\text {Aff1 }}$

Aff1 Imperial College School of Medicine, London, UK

\section{Keywords}

Gene, linkage, osteoarthritis

\section{Context}

Osteoarthritis $(\mathrm{OA})$ is a common rheumatic disease. The aetiology is not known, although a plethora of biochemical abnormalities within cartilage and bone have been described. Epidemiological data suggest that $\mathrm{OA}$ is a complex genetic trait, and some candidate genes have been implicated, including COL2A1, and loci on 1p, 8q and 11q. The phenotype is varied, and determination of heritability confounded by clinical subphenotypes. Furthermore, there is a progressive increase in disease frequency such that age criteria are an important parameter in defining a sample population of OA. A genetic contribution is most evident when onset is at a younger age and appears to influence the type of OA. For example, knee OA in females, and symmetrical distal interphalangeal (DIP) joint disease with Heberden's nodes, are subject to distinct genetic influences. The quoted prevalence of severe hand OA in the 50-59 year age group in Finland is $0.18 \%$.

To map loci linked to DIP joint OA in a Finnish population.

\section{Significant findings}

The initial genome-wide screens mapped six loci with $Z>1.00$ (MLINK) and two loci with $Z>1.00$ (SIBPAIR). In the second phase of the analysis, the loci with the strongest linkage were situated on chromosome $2(\mathrm{C} 2)$. All three programs used raised the possibility that there were two loci in the region 2q11-2q24. The strongest (SIMWALK LOD $=4.0$ ) was at IL1R1 (interleukin 1 type 1 receptor), with a second peak some $38 \mathrm{cM}$ distal to this. In view of the strength of linkage at IL1R1, this region was examined for linkage disequilibrium, although the sample sizes were limited $(\mathrm{n} 1=37$ and $\mathrm{n} 2=32$ ), evidence for disequilibrium in this region was obtained, $P=0.05$ ). Other replicated loci were on 4q26-q27 ( $\mathrm{Z}=1.7$ ? 1.9), 7p15-p21 ( $\mathrm{Z}=1.1$ ? 1.3), and 9q33-q34 $(\mathrm{Z}=2.2)$. The $\mathrm{C} 9$ locus was not corroborated by multi point allele sharing analysis. 


\section{Comments}

This study is a well-designed analysis of linkage in a defined subgroup of patients with OA. It was performed on the Finnish cohort. The Finnish population presents advantages of a founder effect and relatively isolated expansion. Although these factors increase the validity of a model-based linkage analysis, as used in the first screen, there are some limitations. To what extent can the results obtained in a Finnish population be extrapolated to other populations? In this regard it is interesting to note the colocalisation of the region on the short arm of $\mathrm{C} 2$ in a UK study. As there is evident disequilibrium across proximal 2q, analysis of different population samples may allow the more rapid identification of aetiological polymorphisms contained therein.

\section{Methods}

A two-stage protocol involving microsatellite marker analyses and multiple linkage methods was employed. Finnish patients with hand OA were recruited from three previous epidemiological studies. From a total of 285 potential subjects, a total of 64 subjects (27 sibships) were recruited. Their mean age at phenotyping was 58.9 years. In the first stage of the analysis, affected individuals were genotyped with a standard set of 302 genome-wide microsatellite markers. In a second stage, a threshold LOD Z score of 1.00 was used to instigate a dense genotyping at candidate loci, using markers selected from a variety of databases. In the first stage, the program MLINK was used in a two-point, affected-only analysis (allele frequencies were estimated from the sample population). An affected sib pair (ASP) analysis was conducted using the SIBPAIR program. In the second stage, candidate regions were scrutinised with the program POLYLOCUS (which adds in linkage data from adjacent markers) and with SIMWALK 2.40 a program designed to implement nonparametric multipoint linkage.

\section{References}

1. Leppavuori J, Kujala U, Kinnunen J, Kaprio J, Nissilo M, Heliovaara M, Klinger N, Partanen J, Terwilliger JD, Peltonen L: Genome scan for predisposing loci for distal interphalangeal joint osteoarthritis: Evidence for a locus on 2q. Am J Hum Genet . 1999, 65: 1060-1067.

This PDF file was created after publication. 